\title{
Brown-bagging Granny Smith apples on trees stops codling moth damage
}

\author{
Walter J. Bentley $\quad$ Mario Viveros
}

\begin{abstract}
In a 2-year study, thinning Granny Smith apples to one per cluster and covering them with brown paper bags when they were the size of a golf-ball resulted in significantly fewer fruits damaged by codling moth compared with fruits hand-thinned and left untreated. Sunburned fruit were also reduced both years by bagging, and fruit firmness and sweetness were improved in 1 of the 2 years. A similar experiment is now underway with Fuji apples.
\end{abstract}

During 1989 and 1990, field trials were conducted in a commercial apple orchard near Arvin, California, to evaluate the feasibility of growing Granny Smith apples in home gardens without using insecticides to control codling moth. Instead, small, brown paper bags were placed around individual apples as a barrier to oviposition by moths. The bags also protected the apples from sunburn. The Granny Smith cultivar was chosen because of its long period between bloom and harvest when the probability of infestation increases.

Since it was first detected in 1747 in an area that would soon become the United States, codling moth, Cydia pomonella (Linnaeus), has become the major pest of apples. In addition to apples, codling moth infests English and Asian pears, English walnut, quince, crab apple, hawthorne, and various stone fruits. However, apple and pear are preferred; when left unsprayed, a complete crop loss can result. In the southern San Joaquin Valley, codling moth is particularly troublesome because it can complete four generations in most years.

Home gardeners in particular are troubled by codling moth. Many do not

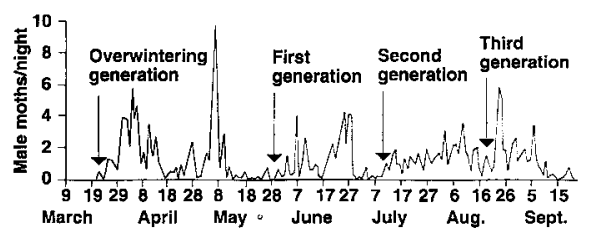

Fig. 1. Seasonal flight of codling moth, Arvin, California, 1990. understand the importance of appropriately timing insecticide sprays. Often, they are applied when they do the least good, leading gardeners to step up the dosage or the frequency of application. That, in turn, can lead to unacceptable residues on fruit. Some gardeners are reluctant to apply synthetic materials and are unable to harvest fruit without worms. Many give up trying to grow apples.

\section{Codling moth behavior}

Female codling moths lay eggs either on leaves or on developing fruit. After the eggs hatch, the larvae enter the fruit through the calyx end, where two fruit touch, or along the sides of the fruit. Once in the fruit, they quickly move to the core where they feed on seeds and then exit to pupate or to overwinter as mature larvae in silken cocoons. Overwintering larvae can be found under tree bark, under plant debris, or on the soil. By March, wintering larvae are pupating and adult moths begin emergence.

Overwintering moth emergence extends from March through late May in the San Joaquin Valley, and in most years two distinct flight peaks occur. First summer generation flight occurs from early June through early July. By mid-July second summer generation adults are active; the third summer generation occurs in late August into September. Activity in the fourth and final flight (third summer generation) is not as prolonged as the previous flights. Typical seasonal flight activity is seen in figure 1 .

Control of codling moth has been traditionally based on timely insecticide applications. If minimal sprays are to be used, they must be timed at egg hatch so that the larvae will pick up a lethal dose upon contact or while feeding. The only alternative to timing insecticides has been a calendarbased spray schedule. In areas with four generations, this could result in as many as 12 sprays with organophosphate or carbamate insecticides to keep apples worm free. If biological insecticides - such as various formulations of Bacillus thuringiensis $(\mathrm{Bt})$ - are used, as many as 24 sprays could be required, with weekly applications from mid-March through August. This procedure is sometimes used by those attempting to market apples under the organic label.

\section{The field trials}

Twenty-four trees selected for the field trials, among the 518 grown per acre, were on a two-wire trellis with a 14- by 6-foot planting density. The trees, ranging in height from 12 to 15 feet and irrigated with low-volume sprinklers, received a standard dormant spray with an organophosphate and a supreme oil for control of San Jose scale and rosey apple aphid. No other pesticides were applied during the study.

The field trial consisted of three treatments applied to single trees and replicated eight times. The treatments in-

TABLE 1. Proportion of codling moth-infested Granny Smith apples at harvest

\begin{tabular}{llr}
\hline & \multicolumn{2}{c}{$\begin{array}{c}\text { Percentage } \\
\text { infestation* }\end{array}$} \\
\cline { 2 - 3 } Treatment & $\mathbf{1 9 8 9}$ & 1990 \\
\hline Bagged + thinned & $0.4 \mathrm{a}$ & $1.3 \mathrm{~A}$ \\
Thinned & $2.2 \mathrm{~b}$ & $21.5 \mathrm{~B}$ \\
Nonthinned & $2.5 \mathrm{~b}$ & $24.5 \mathrm{~B}$ \\
\hline
\end{tabular}

"Means followed by the same letter in columns are not significantly different at the $5 \%$ level (lowercase) and $1 \%$ level (uppercase) by Duncan's multiple range test. (Harvested September 7, 1989, and August 29,1990$)$.

TABLE 2. Granny Smith apple yield

\begin{tabular}{lrr}
\hline \hline & \multicolumn{2}{c}{$\begin{array}{c}\text { Lbs. of fruit } \\
\text { per tree* }\end{array}$} \\
\cline { 2 - 3 } Treatment & \multicolumn{1}{c}{1989} & 1990 \\
\hline Bagged + thinned & $62.5 \mathrm{~A}$ & $72.3 \mathrm{~A}$ \\
Thinned & $90.7 \mathrm{~B}$ & $53.8 \mathrm{~A}$ \\
Nonthinned & $111.7 \mathrm{~B}$ & $68.1 \mathrm{~A}$ \\
\hline
\end{tabular}

"Means followed by the same letter in columns are not significantly different at the $1 \%$ level, by

Duncan's multiple range test. (Harvested September 7,1989 , and August 29, 1990).

TABLE 3. Dropped Granny Smith apples infested with codling moths

\begin{tabular}{lc}
\hline \hline Treatment & $\begin{array}{c}\text { Average number } \\
\text { per tree* }\end{array}$ \\
\hline Bagged + thinned & $0.4 \mathrm{~A}$ \\
Thinned & $11.0 \mathrm{~B}$ \\
Nonthinned & $19.6 \mathrm{~B}$ \\
\hline "Means followed by the same letter are not signifi- \\
cantly different at the 1\% level, by Duncan's multiple \\
range test. (Counted August 9, 1990).
\end{tabular}


cluded: (1) bagging individual fruit after hand-thinning to one per cluster, (2) handthinning fruit to one per cluster but not bagging them, and (3) not thinning or bagging.

The bags used were \#2 Townsend paper bags measuring $18.5 \mathrm{~cm}$ by $10.5 \mathrm{~cm}$. In bagging, we wanted a fairly tight seal around the stems. To achieve this, a $5-\mathrm{cm}$ slit was made in the bottom of the bag. This opening was slipped over the fruit and formed a seal around the stem. The open end was then stapled shut. In 1989, the apples were thinned and bagged on May 16, with the diameter of fruit averaging approximately $4 \mathrm{~cm}$. They were harvested September 7. In 1990, thinning and bagging was performed on May 1 on fruit averaging $2.4 \mathrm{~cm}$ in diameter. Harvest occurred August 29, 1990.

Several parameters were evaluated. All the fruit on the 24 trees studied were harvested and evaluated for yield, codling moth infestation, and sunburn severity. Sunburned fruit was divided into four cat- egories: category 1 , no evidence of sunburn; category 2, slight yellowing; category 3 , a uniform yellowing of an exposed side; and category 4, some browning. Because the number of fruit varied from tree to tree, results of both codling moth infestation and sunburn are expressed as percentage of yield.

Subsamples of 20 apples in 1989 and 24 apples in 1990 were taken from each tree in the test. These fruits were evaluated for soluble solids, firmness, and size. The number of infested fruit that had dropped from trees was also counted in 1990.

\section{Results}

Bagging individual apples significantly reduced $(P<0.05,1989 ; P<0.01,1990)$ infestation over the two non-bagged treatments (table 1).

Under low codling moth infestation (1989), the bagged and thinned treatment resulted in the lowest total fruit yield ( $\mathrm{P}<$ 0.01 , table 2). Where infestation levels reached $20 \%$ (1990) there was no statistical

\begin{tabular}{|c|c|c|c|c|c|c|c|c|}
\hline \multirow[b]{3}{*}{ Treatment } & \multicolumn{8}{|c|}{$\begin{array}{l}\text { TABLE 4. Proportion of sunburned fruit classed into four categories* } \\
\text { Percentage of yield (lb) in each category }{ }^{*}\end{array}$} \\
\hline & \multicolumn{2}{|c|}{1} & \multicolumn{2}{|c|}{2} & \multicolumn{2}{|c|}{3} & \multicolumn{2}{|c|}{4} \\
\hline & 1989 & 1990 & 1989 & 1990 & 1989 & 1990 & 1989 & 1990 \\
\hline Bagged + thinned & $86.5 \mathrm{~A}$ & $96.1 \mathrm{~A}$ & $8.0 \mathrm{~A}$ & $3.1 \mathrm{~A}$ & $3.8 \mathrm{~A}$ & $0.6 \mathrm{~A}$ & $1.8 \mathrm{~A}$ & $0.3 \mathrm{~A}$ \\
\hline Thinned & $48.2 \mathrm{~B}$ & $72.9 \mathrm{~B}$ & $23.7 \mathrm{~B}$ & $18.0 \mathrm{~B}$ & $18.8 \mathrm{~B}$ & $5.6 \mathrm{~B}$ & $9.4 \mathrm{~B}$ & $3.5 \mathrm{~B}$ \\
\hline Non-thinned & $52.5 \mathrm{~B}$ & $69.6 \mathrm{~B}$ & $20.4 \mathrm{~B}$ & $19.1 \mathrm{~B}$ & $16.7 \mathrm{~B}$ & $6.2 \mathrm{~B}$ & $10.4 \mathrm{~B}$ & $5.2 \mathrm{~B}$ \\
\hline
\end{tabular}

*Categories: (1) no sunburn, (2) slight yellowing, (3) uniform yellowing, (4) browning.

†Means followed by the same letter in columns are not significantly different at the $1 \%$ level, by Duncan's multiple range test. (Harvested September 7, 1989 and August 29, 1990.)

TABLE 5. Quality effects of bagging and thinning Granny Smith apples

\begin{tabular}{|c|c|c|c|c|c|c|}
\hline \multirow[b]{2}{*}{ Treatment } & \multicolumn{2}{|c|}{$\mathrm{PSI}^{*}$} & \multicolumn{2}{|c|}{ Soluble solids ${ }^{*}$} & \multicolumn{2}{|c|}{ Diameter $(\mathrm{mm})^{*}$} \\
\hline & 1989 & 1990 & 1989 & 1990 & 1989 & 1990 \\
\hline Bagged + thinned & $18.8 \mathrm{~A}$ & $20.2 \mathrm{~A}$ & $14.2 \mathrm{~A}$ & $13.0 \mathrm{~A}$ & $73.5 \mathrm{~A}$ & $73.6 \mathrm{~A}$ \\
\hline Thinned & $17.9 \mathrm{~B}$ & $20.0 \mathrm{~A}$ & $13.7 \mathrm{~B}$ & $12.9 \mathrm{~A}$ & $74.1 \mathrm{~A}$ & $74.9 \mathrm{~A}$ \\
\hline Nonthinned & $17.5 \mathrm{~B}$ & $20.2 \mathrm{~A}$ & $13.5 \mathrm{~B}$ & $13.0 \mathrm{~A}$ & $71.9 \mathrm{~B}$ & $71.9 \mathrm{~B}$ \\
\hline
\end{tabular}

*Means followed by the same letter in columns are not significantly different $(P<0.01)$, by Duncan's multiple range test. (Harvested September 7, 1989 [20 fruit per plot] and August 29, 1990 [24 fruit per plot].)

TABLE 6. Cost/revenue comparison of bagging and thinning with chemical pest control and thinning for Granny Smith apples*

\begin{tabular}{|c|c|c|}
\hline \multirow[b]{2}{*}{ Operation } & \multicolumn{2}{|c|}{ Treatment } \\
\hline & $\begin{array}{l}\text { Chemical thinning } \\
\text { and pest control }\end{array}$ & $\begin{array}{l}\text { Hand thinning } \\
\text { and bagging }\end{array}$ \\
\hline \multicolumn{3}{|c|}{ Codling moth control and thinning costs/ac* } \\
\hline Materials @ 4 treatments/act & $\$ 140.00$ & $\$ 2,274.00$ \\
\hline Equipment & $\$ 75.00$ & NA \\
\hline Labor & $\$ 25.00$ & $\$ 7,770.00$ \\
\hline Total cost/ac & $\$ 240.00$ & $\$ 10,044.00$ \\
\hline \multicolumn{3}{|l|}{ Additional cost/ac } \\
\hline (bagging costs minus chemical cost) & NA & $\$ 9,804.00$ \\
\hline Marketable yield/ac† & $27,226 \mathrm{lb}$ & $35,804 \mathrm{lb}$ \\
\hline Estimated return/lb & $\$ 0.15$ & $\$ 0.15$ \\
\hline Revenue/ac & $\$ 4,083.90$ & $\$ 5,370.60$ \\
\hline Increased return/ac with bagging & NA & $\$ 1,286.70$ \\
\hline Net loss/ac (total revenue minus cost) & NA & $\$ 8,517.30$ \\
\hline \multicolumn{3}{|c|}{$\begin{array}{l}\text { "Other costs of production assumed to be equal, yield of } 230 \text { fruit/tree and labor based on } 3 \text { man-hours/tree } \\
\text { (bagging and thinning) at } \$ 5 / \mathrm{hr} \text {. Four treatments assumed for codling moth control to equal the bagged treat- } \\
\text { ment. } \\
\dagger \text { Based on marketable yields of } 72 \mathrm{lb} / \text { tree with } 518 \text { trees per acre and sunburn ( } 4 \% \text { sunburn in bagged and } \\
73 \% \text { in non-bagged). }\end{array}$} \\
\hline
\end{tabular}

difference among treatments due to fruit loss from codling moth. However, more apples were harvested from the bagged and thinned treatments than from the others.

Where infestation levels are high, the percentage of infested fruit can be misleading. This is primarily a measure of fruit damaged by the last generation. Strikes by worms in earlier generations will fall from the tree and not be included as infested. On August 9, dropped infested fruit under the trees were counted. There were significantly fewer fruit dropped under the trees with bagged fruit $(\mathrm{P}<0.01$, table 3).

Bagging individual fruit significantly reduced the amount of sunburn over the two non-bagged treatments in categories 2, 3, and $4(\mathrm{P}<0.01$, table 4$)$, both in 1989 and 1990. Correspondingly, the amount of fruit in category 1 was significantly greater for the bagged treatment $(\mathrm{P}<0.01$, table 4 ).

The quality of fruit was improved by bagging in 1989 but not in 1990 (table 5). Both firmness and percent soluble solids were significantly higher $(\mathrm{P}<0.01)$ in 1989. Thinning the fruit, irrespective of bagging, resulted in significantly larger fruit $(\mathrm{P}<0.01$, table 5). This was true in both 1989 and 1990.

\section{Practical application}

Although bagging of apples has been practiced in Japan, most feel the cost and intense labor demanded do not make this process feasible for commercial apple production in the United States. What would a grower have to do to make a profit equal to a conventional program? Table $6 \mathrm{com}$ pares the per-acre cost in the San Joaquin Valley under a standard chemical program with that of a bagging program, other production practices are assumed to be equal. Listed are only those costs that would differ with bagging.

In this study, 3.2 man-hours (rounded to 3 man-hours in table 6) per tree were required in both 1989 and 1990 to thin, bag, and staple bags closed. The average number of fruit bagged per tree was 190 in 1989 and 231 in 1990. Assuming the same yields and low amount of sunburn obtained during the study's second year, 518 trees per acre and 15 cents a pound $(\$ 300$ per ton) received by the farmer, bagging fruit would cost an additional $\$ 8,517$ per acre in spite of the increased marketable yield resulting from sunburn protection and codling moth protection. Only if the fruit were sold for 36 cents per pound, more than double the price of 15 cents, could the grower arrive at a point equal to that in a chemical control program.

This technique does show, in principle, Granny Smith apples can be protected from codling moth infestations and from 
sunburn by protecting fruit throughout the growing season with paper bags. As much as 30 to $40 \%$ additional yield in Grade 1 fruit can apparently be achieved with bagging in the southern San Joaquin Valley compared with nontreatment. This is mainly thanks to sunburn protection. Sunburn protection may not be as necessary in other parts of California where summers are not as hot. Where high winds occur and make paper bags not feasible, cloth bags with string ties could be used to provide comparable protection.

For individuals with few trees, bagging can result in quality fruit without significant loss due to codling moth or sunburn. This technique should be applicable to other apple cultivars as well, and at present a similar experiment with Fuji apples is underway. The experiment with Fuji apples may be commercially feasible inasmuch as consumers are apparently willing to pay top price for them. The technique should also be useful for Asian pears, which have to be thinned heavily and are therefore more expensive than other pears on the market.

Bagging can be done on the entire tree or on as many fruit as desired. This technique takes more time than spraying, but it demonstrates that apples can be grown without insecticides under heavy codling moth pressure during a long growing season. It also eliminates the problem of pesticide disposal often encountered by gardeners.

W. J. Bentley is Extension Entomologist and Mario Viveros is Extension Pomologist with UC Cooperative Extension, Kern County.

The authors wish to thank Martha

Gonzalez, John Fritz, Lynette Beurman, and Nancy Medina for treatment and harvest assistance, as well as John Wood and Jim Carlisle of Green Valley Fruit for providing a site and managing the trial.

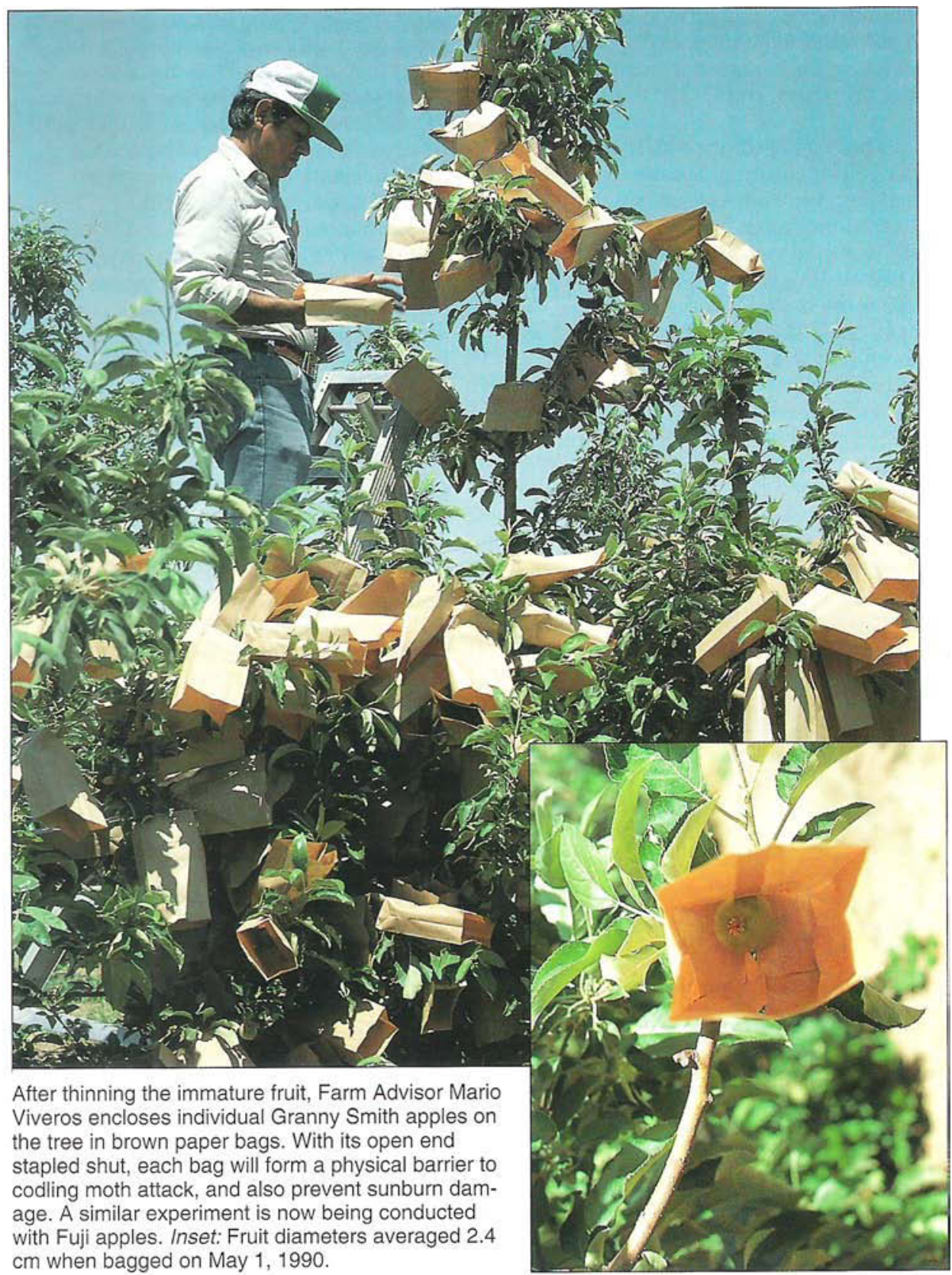

CALIFORNIA AGRICULTURE ASSOCIATE EDITORS

Animal, Avian, Aquaculture and Veterinary Sciences

Richard H. McCapes

(2nd assoc. editor to be announced)

Economics and Public Policy

Harold O. Carter

(2nd assoc. editor to be announced)

\section{Food and Nutrition}

Eunice Williamson

Human and Community Dovelopment Linda M. Manton

Karen P. Varcoe

\section{Land, Air \& Water Sciences}

Garrison Sposito

Henry J. Vaux, Jr.

Natural Resources

Daniel W. Anderson

John Helms

Richard B. Standiford

Pest Management

Thomas C. Baker

(2nd assoc. editor to be announced)

Plant Sciences

Calvin O. Qualset

G. Steven Sibbett

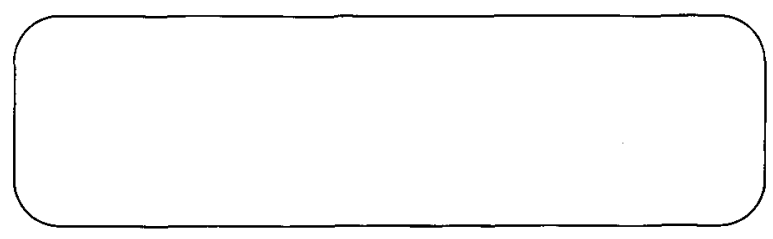

